\title{
Older adults and violence: \\ An analysis of domestic homicide reviews in England involving adults over 60 years of age
}

\author{
Benbow, Susan Mary ${ }^{1,2}$ * \\ Bhattacharyya, Sarmishtha ${ }^{1,3}$ \\ Kingston, Paul ${ }^{1}$ \\ ${ }^{1}$ Centre for Ageing Studies, University of Chester, Riverside Campus, \\ Chester, CHA, 1SL, UK. \\ 2 Older Mind Matters Ltd, Manchester, UK. \\ ${ }^{3}$ Betsi Cadwaladr University Health Board, North Wales. \\ * Corresponding author: Dr Susan M Benbow, Visiting Professor of Mental \\ Health andAgleing, Centre for Ageing Studies, University of Chester, \\ Riverside Campus, Chester, CH1, 1SL, UK. \\ Phone: 07789485435 \\ Email: drsmbenbow@gmail.com
}

Email P. Kingston: p.kingston@chester.ac.uk

Email S. Bhattacharyya: drsharmib@gmail.com 


\section{Abstract}

Domestic Homicide Reviews (DHRs) are conducted when an individual aged 16 or over appears to have died from violence, abuse or neglect by a person to whom they are related or with whom they are in an intimate relationship or who is a member of the same household. DHRs aim to identify lessons to be learned, to improve service responses to domestic abuse, and to contribute to prevention of domestic abuse/ homicide. We submitted freedom of information requests to English Local Authorities to identify DHRs where victim perpetrator, or both were aged over 60. Collected Reports and or Executive Summaries were thematically analysed. Analysis identified four key themes in the context of the key relationship and caring: major mental illness of the perpetrator; drug and/or alcohol abuse; financialissues; and a history of domestic abuse in key or family relationships. We analysed 14 adult family homicides, 16 intimate partner homicides, and five homicide-suicides. Age per se did not emerge as a significant factor in our analysis. Terminology needs to be standardised, and raining/ education regarding risk assessment improved in relation to age, myths around ageing/ dementia, and stresses of caring. Management of mental illness is a key factor. A central repository of DHR Reports accessible for research and subject to regular review would contribute to maximising learning and improving practice.

\section{Key words}

adult family violence

caring

dementia

domestic abuse 
elder abuse

homicide-suicide

intimate partner violence

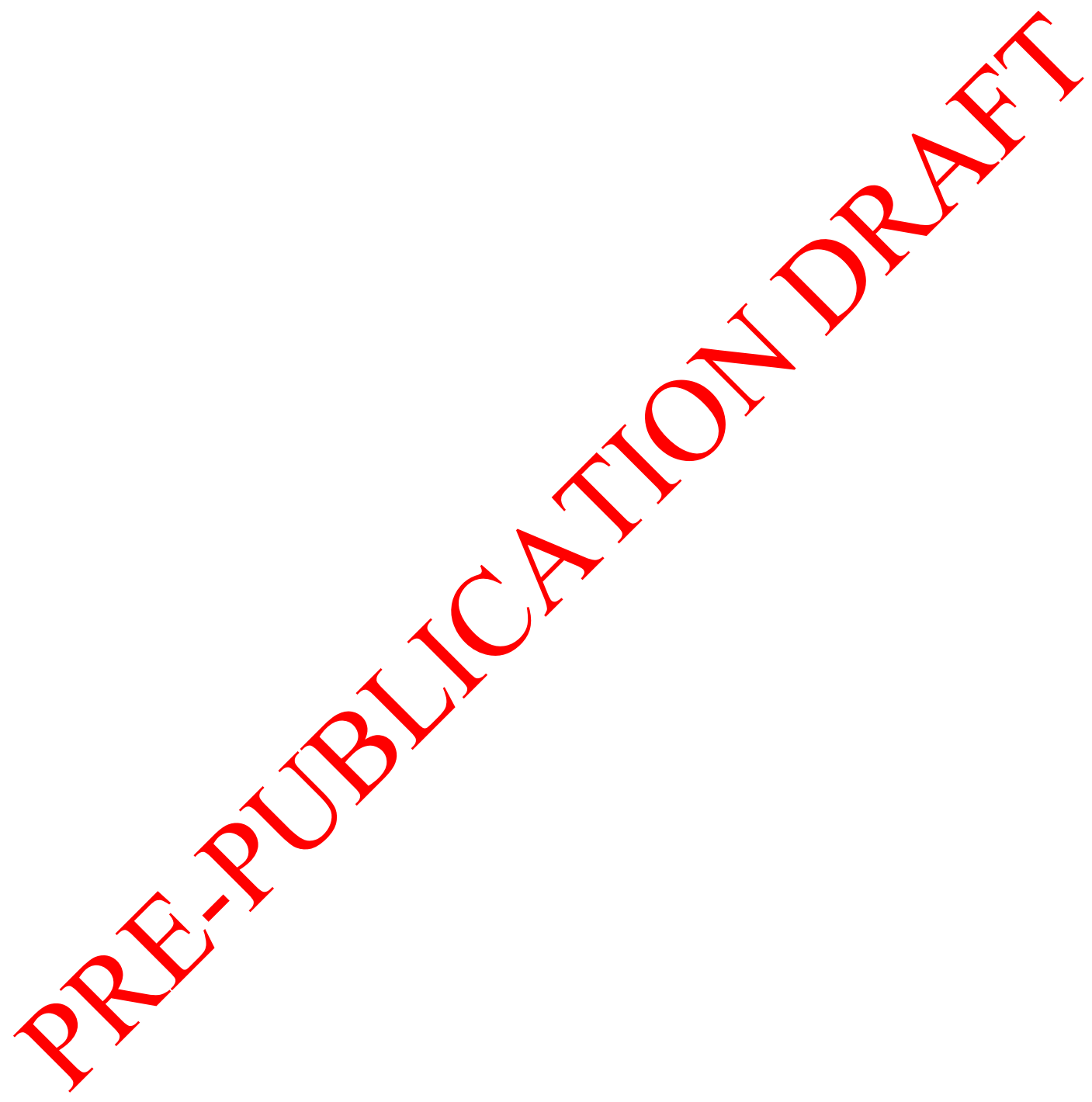




\section{Introduction}

The World Health Organisation estimates that up to $38 \%$ of homicides of women globally are committed by male intimate partners (World Health Organisation, 2014, 2016a): this figure is six times higher for women than the corresponding figure for men (Stöckl et al., 2013). Estimating the prevalence of domestic abuse (DA) in older adults in England is complicated by the fact that the Crime Survey for England and Wales (CSEW) asks adults aged 16 to 59 about intimate violence, but excludes adults aged over 59 . This is likely to be a reflection of institutional and societal ageism, which is alsoexhibited in other areas including sexual health (eg the National Surveys of Sexual Attitudes and Lifestyles (Natsal) extended up to age 74 for the first time in the third survey, 2010-2012 (Mercer et al, 2013) In addition reported cases are likely to under-estimate the true prevalenceyn 2014/2015 the CSEW estimates that $8.2 \%$ of women and $4.0 \%$ of men reported experiencing DA (Office for National Statistics, 2016a).

Key points from Home Office analysis of domestic homicides (Office for National Statistics, 2016b) over a three year period from 2012 to 2015 are: the average age ff domestic homicide victims was men 47 and women 46; 77\% of women domestic homicide victims were killed by a partner/ex-partner, and the remaining $23 \%$ by a family member; $51 \%$ of male domestic homicide victims were killed by a partner/ex-partner and the remaining $49 \%$ by a family member; $97 \%$ of women domestic homicide victims were killed by a male suspect, but only around one third of male domestic homicide victims were killed by a female suspect; the number of women victims aged 75 and over 
was greater than would be expected from population figures (13\% of female homicide victims aged 75 and over, compared with $9 \%$ in the female population); men victims were less likely to be aged 75 and over (4\% compared with $7 \%$ in the population).

\section{Domestic Homicide Reviews}

Statutory Domestic Homicide Reviews (DHR) came into force on $13^{\text {th }}$ April 2011, although some authorities carried out voluntary Reviews before that date. They are carried out under section 9 of the Domestic Yiolence,'Crime and Victims Act (2004) and involve:

"a review of the circumstances in which the death of a person aged 16 or over has, or appears to have, resulted from violence, abuse or neglect by

(a) a person to whom hewas related or with whom he was or had been in an intimate persohal relationship, or

(b) a member of the same household as himself, held with a yiew to identifying the lessons to be learnt from the death". Home Office, 2016a: 5)

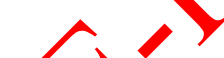

\section{2}

The main Purpose of DHRs, set out in the Home Office Guidance, is:

"to prevent domestic violence and homicide and improve service responses for victims by developing a coordinated multi-agency approach to ensure that abuse is identified and responded to effectively at the earliest opportunity." (Home Office, 2016a: 4) 
Thus domestic homicides are situated within the context of DA. DA refers to a wide range of violent/ abusive behaviours including physical, sexual, financial and emotional abuse. It is complex, often hidden, and there are issues of definition within the broad concept. NICE guidance (National Institute for Health and Care Excellence, 2014: 27) defines DA as follows:

"physical abuse, threats, non-physical abuse, sexual assault or stalking perpetrated by a partner, ex-partner or family member."

This definition includes family members as well as intimate partners, and is broader than the World Health Organisation definition of intimate-partner violence (IPV):

"any behaviour within an intimate relationshe that causes physical, psychological or sexual harm to those in the relationship". (World Health Organisation, 2012: 1)

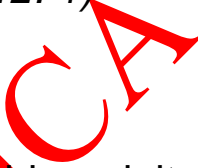

Domestic homicides involying older adults include homicides falling within IPV (sometimes called intirate partner homicides (IPH)); those within the context of elder abuse or adult safeguarding; and those falling into adult family violence (AFV) (cotled adult family homicides $(\mathrm{AFH})$ ).

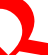

What is known about older victims and perpetrators of intimate partner violence?

Yon et al (2014) reported a qualitative study which compared IPV/ "spousal abuse" among mid-age adults (aged 45-59) and old age adults (aged 60 and over) in Canada. They compared risk and protective factors of abuse across these two age groups and contextualised it within a life course framework. 
They highlighted the spouse's drinking behaviour; being a member of a visible minority; and large age difference between spouses in terms of increasing the risk of reporting spousal abuse, and found that:

"Regardless of age group, having a disability or a long-term physical, mental, or other health problem increases the likelihood of reporting emotional/financial and physical/sexual abuse." (Yon et al, 2014: 95) and suggested that the stress and burden of care-giving might lead to aggression towards the person being cared for. They further conpmented that although this relationship might hold at younger ages it may be-heightened in older adults because of the increased rates of disability and perhaps also complex comorbidities). Similarly, in a Polish survey (Tobiasz-Adamczyk et al, 2014) self-reports of being a victim of violence were significantly more frequent in individuals with poorer health status, increasing with the number of chronic conditions. Poole \& Rietschlin (2012) reported a similar finding.

An increased risk of $1 R V$ for those with a disability fits with other reports. For example Coyne et (1)993) reported that carers who abused the persons with dementia they weye caring for had been caring for more years; were providing care for more hours per day; were caring for more functionally impaired care reciplents; had greater levels of burden and were more depressed. They also found that carers who had been abused by the person they were caring for were more likely to subject that person to abuse. Although dementia can occur across the age range its prevalence increases with age. 
Poole \& Rietschlin (2012) found that overall, $6.8 \%$ of persons over 60 (excluding persons who were never married) experience some type of IPV and over a quarter of them, almost $28 \%$, experience multiple forms of abuse. They investigated personal, relational and environmental factors and highlighted an increased risk of abuse amongst immigrants in current couples. They found that the likelihood of being physically/sexually abused is highest for those in short-term relationships, and that partner characteristics are important, including frequent or heavy alcohol use and lower leve educational attainment or income. They suggest that a partneresendency on the potential victim and ability to handle stress are keyfactors influencing the likelihood of abuse. Persons in current couple kelationships living in a high crime neighbourhood, who are more likely to be socially isolated, are also more likely to experience physical (and emetional) abuse.

A study from China complicated matters by concluding that

" IPV in older couptes is a complex phenomenon that is closely intertwined with ther forms of domestic violence, including spousal violence, child abuse, in-law conflicts, and elderly adult abuse. Thus, oefore we have more definitive and concrete evidence that IPV in older couples should definitively come under the category of elder abuse or $I P V$, it is advisable to treat it under its own separate category of family violence." (Yan and Chan, 2012: 1437)

Thus there are features associated with older age that may be particularly important in IPV towards older adults. 
What is known about elder abuse?

One complication for older adults is that the NICE definitions of DA and IPV overlap with elder abuse, defined by the WHO as:

"a single or repeated act, or lack of appropriate action, occurring within any relationship where there is an expectation of trust, which causes harm or distress to an older person." (World Health Organisation, 2016b)

The inclusion of an "expectation of trust" arguably sets elder abujeapart from DA (BMA Board of Science, 2014), but trust is not unusuarin otose relationships leaving the boundary unclear. Confusingly the concept of trust is not found in the Care Act (2014) which sets out egislatton for adult safeguarding, including safeguarding from domestic violence.

Ironically, little research has been conducted to understand the relationship between elder abuse and DA, and existing reports mainly consider women as victims and men as perpetrators. Yon et al (2017) in a systematic review and meta-analysis found a combined prevalence for overall elder abuse in the past year of 14,1\%. They argue that:

Fewresearch studies have compared abuse of women across age groups. One study found IPV is more prevalent later in adulthood at $41 \%$ for women aged 45 years and older, compared to $36 \%$ women aged 30-44 years and 26\% 18-29 years (Wilke and Vinton, 2005)". (Yon et al, 2017: 9)

This illustrates the overlap between IPV and elder abuse. Yon et al. (2017) subsume IPV in older women into elder abuse, and note that: 
"it is plausible that with increasing age, intimate partners are less physically capable of perpetrating the more 'traditional' forms of IPV (i.e., physical and sexual) ..." (p.9)

Recently Labrum and Solomon (2017) have highlighted the established link between elder abuse and abusers with substance misuse and/or mental health conditions. Liu et al. (2017) also argue the importance of abuser characteristics: they found that abuser characteristics (rather than vietim vulnerabilities) predicted emotional/psychological abuse, drawing attention to three factors, an emotionally draining abuser/ victim relationsalip;ábusers' poor temper control; and abusers' angry feelings towards their victims.

Adult Family Violence

AFV overlaps with elder abuse and may be,defined to include or exclude IPV, for example:

"any form of abuse, mistreatment or neglect that an adult experiences from a family nenaber? Family violence includes many different forms of physical andembtional abuse, as well as neglect carried out by family menabers. It may include a single act of violence, or a number of acts that form a pattern of abuse." (Department of Justice Government of Cánada, 2015)

In our study we distinguish IPV from AFV. An additional consideration is that studying domestic homicides involving older adults necessitates a decision on what age constitutes a transition into later life/ older age. Literature on DA often uses the age of 60 or 65 as a defining point of old age/ later life. We use 
60 as the age marking transition into later life, in line with historical retirement policies and service transitions to older adult services.

\section{Aims}

This analysis considers DHR Reports where the homicide involved an older adult (aged over 60 years) as victim only, perpetrator only, or both victim and perpetrator. Our aims were to:

1. extract learning relevant to health and social care practitionerstworking with older adults in the community (eg GPs, community nurses) and in hospitals (eg staff in emergency departments): they encounter victims and perpetrators, and carry out risk assessments.

2. investigate if there are distinctive featuresin domestic homicides involving older adults - is age a significant risk factor in domestic homicides? and 3. contribute to the researeh literature by investigating a group of victims and perpetrators of violence who have attracted relatively little research attention previously. Older victims and perpetrators are involved in a small proportion of incidents of domestic violence and domestic homicide and their particular characteristics may therefore be obscured.

\section{Methods}

The Freedom of Information Act, 2000, gives the public right of access to information held by public authorities under the jurisdiction of the United Kingdom (UK) Parliament (Information Commissioner's Office, 2016). We 
submitted Freedom of Information (Fol) requests to all local authorities in England. The request was:

1. How many Domestic Homicide Reviews has your authority completed between April 2011 and May 1st $2015 ?$

2. In how many of your authority's Domestic Homicide Reviews completed since April 2011 was the victim aged 60 years or older (but the perpetrator aged below 60 years of age)

3. In how many of your authority's Domestic Homidide ReViews completed since April 2011 was the perpetrator or atleged perpetrator aged 60 years or older (but the victim aged below 60 years of age)?

4. In how many of your authority's Domestic Homicide Reviews completed since April 2011 were both victim AND perpetrator/ alleged perpetrato aged 60 years or older?

5. Where are your Domestic Homicide Review reports published? Ifoossible please provide a weblink.

6. please identify which of your authority's published Domestic Homicide Review reports relate to:

a) victim ONLY aged 60 years or older

b) perpetrator/ alleged perpetrator ONLY aged 60 years or older

c) victim AND perpetrator aged 60 years or older

Where an authority replied that the information was held by another authority, a further request was submitted to the other named authority (including Police forces) and, if information covering the original area was obtained, this was 
counted as a positive response. If a response was ambiguous, a supplementary Fol request was submitted requesting clarification.

Where possible we obtained copies of the DHR Reports and analysed them utilising NVivo, a qualitative data analysis computer software package (Bazeley and Jackson, 2013; QSR International, 2016). All Reports were read in full by two authors. One author coded the transcripts and texts thematically by reading and re-reading the source material in order to identify themes. Thematic analysis was the preferred analytical approach as the project was concerned with content rather than structure and aimed to explore commonalities and differences in the data in ordento identify recurring themes and patterns (Braun and Clarke, 2006). The approach was not situated in a particular philosophical stance or theoreticalyramework. Thematic analysis followed the following process: familiakisation with the data; search for themes; review and clarification of themes; naming and definition of themes; synthesis of the overanalysis. Emerging themes were discussed, refined, clarified and named by) two of the research team in partnership. Ethical approval was nothecessary as the study involved secondary analysis of existing public documents.

\section{Findings}

Two hundred and forty authorities were sent a Fol request, and 184 responded. Fifty-six authorities did not produce any information and no information for DHRs in their areas was obtained from any other source: in a 
majority (45/56) the relevant authority replied to say they did not hold any information about DHRs. Only 11 authorities failed to respond at all.

Responding authorities reported 279 completed DHRs in the timeframe specified. Sixty-three DHRs were initially identified as including an adult over 60 as victim, perpetrator or both. We obtained copies of 31 of these 63 DHRs: full Reports were obtained for 28 and the executive summary for three reviews. One of the latter was obtained by direct request: the authority had stated that the DHR had been published for 24 hours only. Qf 32 Reports not obtained, and where a reason for the Report's unavailability was given, ten were not yet published; nine were with the Home Qffice, and five awaited approval for publication.

After analysis, we searched online for press coverage of the homicides to fill in missing demographic information (ethnicity was commonly redacted in published Reports and semetimes age). At this stage it appeared that two Reports had been misclassified in one authority's response. One DHR reported toinvolve victim aged over 60 appeared to match press coverage of a homicide where the perpetrator was aged over 60 and the victim below 60. A second homicide, said to relate to a victim aged over 60, appeared to match press coverage of a homicide where neither party was aged over 60 . A follow up Fol request was made to the authority asking them to check the original response: an amended response confirmed information extracted from online press coverage. The analysis was re-run after correction. 
Therefore the final analysis included 27 DHR Reports and three executive summaries from a total of 62 DHRs.

Seven Reports involved both victim and perpetrator aged over 60. In these homicides all the victims were women; all the perpetrators were men; and all the relationships were spouse/ partners. Table 1 sets out basic demographic details. Charges were brought in three homicides, resulting in two hothicide, convictions and one manslaughter conviction. In one case a life sentence was imposed. In another homicide there was a Mental Health Actedispósal and no charge was brought. In this group major mental illness eclipsed other factors.

Six Reports related to homicides where the perpetrator was aged over 60 (victim aged below 60). All victims were women, and all perpetrators men. All relationships were spouse/ partrer or ex spouse/ partner. Charges resulted in four homicides and led to three homicide convictions, one manslaughter conviction, and four sentences of life imprisonment. This group was more heterogeneous than homicides involving both parties aged over 60, but mental illness appeared to play a major role.

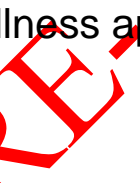

Seventeen DHRs involved victims aged over 60 (perpetrators aged below 60). Eleven of the 17 victims were women and six men. Sixteen perpetrators were men: one was a woman, assisted by a man. In only three homicides was the victim-perpetrator relationship that of partners/ ex-partners (including one gay couple). In 12 homicides an adult son killed a parent (nine mothers, three fathers) and in two an adult grandson killed a grandparent (one step 
grandmother, one grandfather). One homicide took place in a Care Home. Fourteen of these homicides could be described as AFH and three as IPH. Charges were brought in all cases and resulted in seven homicide convictions and nine manslaughter convictions (one outcome unknown). Six life sentences were imposed and there were eight Mental Health Act disposals. Major mental illness in an adult son was a predominant feature of this group, plus a group of homicides characterised by complex family/ relationship issues in combination with drug and/ or alcohol abuse.

$<$ Table 1 about here>

Thematic analysis

Context: Key Relationship and Caregiving

Relationships between those in olved in the homicide varied from "close and loving" (B18), and "positive and supportive ... mutual care and concern" (P03), to others known to be under stress, described as "fraught and tense" (B06), "turbulent" (P04) Nove hate" (V04), and "volatile" (V29). One couple, where the husband killed his wife, was described as "isolated" and "kept themselves to themselves" (V06).

One factor influencing victim-perpetrator relationships was caregiving, related to physical illness, mental illness or both. In 11/30 reviews the victim cared for the perpetrator; in 7/30 reviews the perpetrator cared for the victim; and in 12 reviews neither party was a carer. In one case a husband who killed his wife was seen as: 
"a 'devoted carer' who provided 'excellent support' for his wife thus managing risk linked to her illness, as opposed to someone who may pose a risk to her." (B02)

He asphyxiated his wife, who had dementia and Parkinson's disease, then killed himself. In another homicide (B06) a wife cared for her husband who had dementia. He was aggressive and repeatedly assaulted her. She suffered a head injury, refused to attend hospital, collapsed and died some datys later. Her death was deemed the consequence of assault.

Relationship breakdown featured in several homicides. One-woman, who had been the victim of DA during her marriage, started new relationship and was killed by her estranged disabled former huśband shortly after filing for divorce (P04). Another wife, estranged from her husband, moved back to the former marital home to look after him when he was discharged from a mental health unit following treatment for depression. She was later found dead and he had committed suicide (P05)

\section{1}

Caring maxinfluence a relationship between two people in a number of ways. It maype stressful for the carer and/or for the person being cared for, and it maxchange the balance of power. In one Review where a mother was caring for her son with a psychotic illness, the analysis stated that:

"Supporting the victim to see herself as a carer would have ensured her contribution was recognised; that she was involved in planning individual care for the perpetrator and that her own needs were considered. A carer's assessment would have taken into 
account the effect caring was having on the victim and if she felt she was able to continue caring... she was providing substantial care or regular care and this may have affected her health, her ability to look after her home and her social life." (V01)

Where parents were caring for adult children with mental health problems it appeared that their involvement in care planning was limited or absent perhaps because the adult child was seen as responsible in theirown right. Potential vulnerability of the parent/ carer was often not recognised. This may have been compounded by the fact that older people may see themselves as parent or partner rather than carer. Other possibe factors are perceived patient confidentiality and perhaps ageist discounting of the older parent's perspective. Either or both may have influeneed this situation:

"(the mother/ victim) was a potential treasure trove of information about (her son/the perpetrator) and a potential important ally in monitoring his behaviour which went untapped. She was given no opporfunity to be involved or engaged in his care planning process. Insteadshe was kept at the margins of his care. The failure to 入

engage with her was therefore a serious omission on the part of the MHT... (Mental Health Trust) records show that (the son/ perpetrator) did not want his mother to have a carer's assessment when staff approached him on the matter. She herself was never directly offered a carer's assessment and the one offer that was made was indirectly via her son who made the decision to reject it." $(\mathrm{V} 16)$ 


\section{Case study demonstrating ambiguous carer status}

An openly gay man (the victim) whose partner of 30 years died in 2001 developed problems with alcohol. He had physical health problems, walked with a stick and appeared vulnerable and old for his years. He later (2009) contacted a younger man (the perpetrator) through a magazine and began an on-off relationship. He told his family that they were partners and might marry. Professionals attributed falls and injuries to his age, alcohol and/prophysical health, but his family knew that he was being physically abused-and financially exploited. When he was admitted to hospital after an assault the perpetrator identified himself as "carer" and this appeared to be accepted. The victim disclosed to staff three times that he bad been assaulted but no action was taken. After the victim's death, alpost mortem examination:

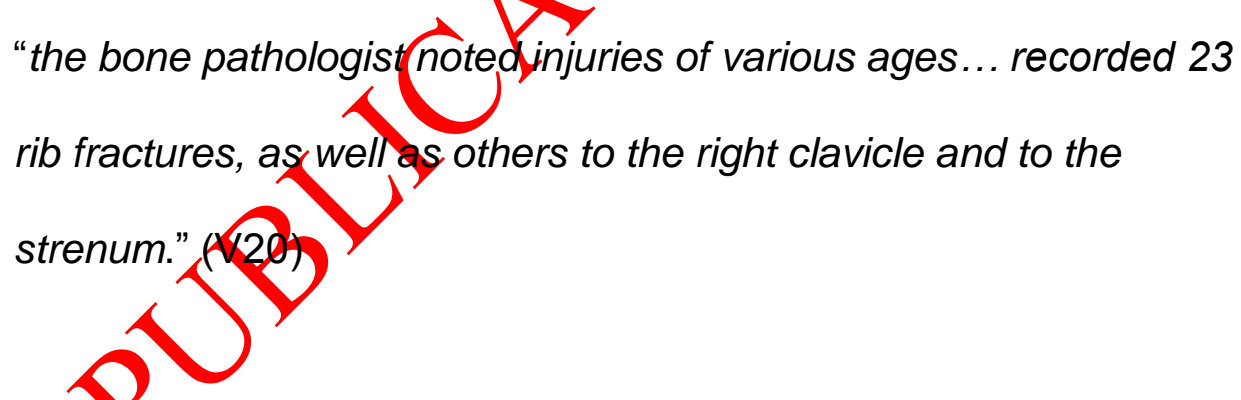

Within the contexty of the key victim-perpetrator relationship, four themes stood out. These are:

1. Mental illness of the perpetrator

2. drug and/ or alcohol abuse

3. financial issues

4. history of DA in this or other family relationships.

Where quotations from Reports are used, they are italicised and indented. 
Theme 1: Major mental illness perpetrator

This is illustrated by a woman who was killed by her husband during a depressive relapse. He had a history of recurrent depressive illness treated successfully with ECT,. No evidence of DA was found during the Review. The General Practitioner (GP) had recorded that the husband was:

"... now worried he will harm himself or harm his wife" (B18)

The relapse had been identified and the man was receiving homptreatment:

"(Family members and a friend) have informed the Revilew that (the wife/ victim and husband/ perpetrator) felt pressurised into accepting home treatment rather than hospital admission and ECT treatment which they knew from experience worked" and "The family believes that if immediate ction had been taken to admit (their father) to hospilat andprovide him with ECT treatment, he would have responded positively as he had on seven previous occasions and therefore their mother would still be alive." (B18)

This Review concluded that the wife's death could not have been predicted and that although admission of the husband to hospital might have prevented the death, decisions made by mental health staff were:

"... reasonable based on the information and policies available to them."

Staff members were, however, unaware of the extent of the husband's past psychiatric history. A similar issue in other cases raises the question of how 
historical information, which might influence risk assessment and treatment plans, is curated and made available to future treatment providers.

In two other cases sons killed a parent:

"the homicide was directly due to the perpetrator's psychotic illness and had been a response to his psychotic experiences: he stated after his arrest that he had killed the "she devil". He said that his mother had "shape changed" into a demon, and that his rage had come from the voices telling him to hurry and kiff the devil" (V01)

"(The perpetrator) had a thirty year periad of treatment by the local mental health services starting in 1982. His diagnosis in 1991 was one of paranoid schizophrenia... The pattern of aggression and paranoia towards his fatherwas also a constant feature prior to his admissions." (V32)

Theme 2: Drug and or alcohol abuse

Drug and/or alcohol abuse was often a factor, and sometimes involved both victimand perpetrator. About a fifth of cases featured alcohol use by the victiph. For example:

"Medical records and information from the family suggest that (the victim) had a significant alcohol abuse problem in the latter stages of her life as well as suffering from depression linked to family bereavements. Likewise (the perpetrator) also had an alcohol abuse problem.." (P03) 
and:

"(the son/ perpetrator) displayed similar traits to (his father/ the victim) in that he was a heavy drinker (family members have described him as being alcohol dependant) ..." (V04)

In over a third of cases the perpetrator misused alcohol, sometimes in combination with drugs eg:

"(the son/ perpetrator) was known to use alcohol in excessand to be an intravenous drug user. His behaviour was difficult and he could be aggressive and threatening. He was a non-complier with treatment..." (V07)

and

"(the son/ perpetrator) was known to,substance misuse and mental health services. He had a long kistory of using illicit drugs and his psychotic episodes were assessed as drug induced." (V22: perpetrator known to abuse hergir and cocaine.)

One of theissues,raised for mental health services was whether a psychotic illness was dpug induced or not:

"The diagnosis for (the perpetrator) has been a constant theme of debate amongst the panel although few members are sufficiently well qualified to make a judgement on the complex state of (his) mental health. (The Mental Health Trust) do not feel "it can rule out the possibility that (the perpetrator) does suffer from a mental illness, such as schizophrenia"." (V22) 
Drug/ alcohol abuse did not rule out a "caring" role:

"an older and chronically unwell woman was living with an adult son with a history of aggression and inappropriate behaviour linked to alcohol and drug use and possible psychosis." (V23)

Reviews involved perpetrators using mephedrone (V28), heroin (V07 V22). cocaine (V22; V23; V31) and amphetamine (V07).

Theme 3: Financial issues (abuse or worries or stealing)

Two Reviews illustrate the role of financial factors. no one case a son with an enduring schizophrenic illness killed his father. The Report notes that the family house and business had been transferred into the son's name after the father was declared bankrupt, a/though the parents carried on living in the house and paying bills.

"... during a ward round, (the perpetrator) again raised the issue of his parents exploiting him financially; however (a team member) stated that (the perpetrator) denied this whilst in the community. the matter of the house ownership and the financial situation was an on-going theme which the staff did not appear to take seriously ..."(V32)

In a second Report

"There is a history of domestic abuse with (the perpetrator) using threatening and aggressive behaviour towards his mother and on occasions his step father to gain money to buy drugs and alcohol. 
When his mother did not provide the money he wanted he would physically assault her by pulling her hair and hitting her predominantly in the face and on the head." (V07)

\section{Theme 4: Previous DA in this or other family relationships}

A clear history of intimate partner DA graduating into later life was uncommon. However it is demonstrated in the Review quoted below where the has band eventually killed the wife:

"It is clear from contact with the family that the histery of domestic abuse goes back more than 25 years. (An adult ohild) said he believes he was about 9 or 10 when hewas first aware of (his father / the perpetrator) assaulting (his mother/ the victim). He described as a child being in bedyand his younger siblings joining him while an argument too Aplace downstairs between their parents. His mother later joined them and sought to give reassurance despite having marks on her face." (P03)

Although adong history of intimate partner DA was unusual, some Reviews foundhistorical evidence of DA in other close family relationships. One son wholater killed his mother had been subjected to regular violence from his father as a child (V16). In another Report a son (who killed his father) was aware that his mother had been subjected to DA during her marriage and:

"... he (the son/ perpetrator) has been similarly accused of domestic related offences against a number of different partners" 
and "he had a tendency to resolve domestic issues by using violence towards his partners". (V04)

Repeated abuse in a parent-child relationship was found in a homicide involving a mother killed by her son:

"There were sixty four incidents of domestic abuse identified by the reviewing Police Officers. 58 occurred (in a two year perigd)." (V07)

This quotation illustrates the complexity of some family relationships:

"... this report paints a picture of (the son/perpetyator) as a young man with limited life skills and borderlinglearning difficulties who grew up in a family where both his parehts drank heavily and there were frequent episodes of domestic violence. (The son/ perpetrator) regularly suffered abuse and was subject to neglect". (V29)

In other homicides no gvidence of previous DA in the key relationship or other family relationships was identified during the Review, but one Report pointed out:

"understanding the influences of coercive control or behaviour on the part of a perpetrator, for example the isolation of the victim, restricting daily activities, intimidation and stifling of independence, are elements that may in fact be present in this case, yet not understood or observed." (V06) 
When conducting DHRs one key decision is how far back to investigate.

Where a perpetrator had dementia one question might be whether the relationship had been abusive prior to developing the dementia, and this would only emerge if records pre-dating the development of the condition were examined. Another factor is that names of partners involved in incidents of DA may not be recorded or may be removed from historical information, so that sometimes a domestic incident had been recorded but it was notknown who was involved.

DHRs involving homicide- suicides

Five Reports involved homicide-suicides, although ene case strictly did not meet the criteria.

VP02 did not strictly fit the definition ofa homicide-suicide (the gap between the homicide and the perpetrator's suicide is commonly defined as one week (Eliason, 2009)), since tbe husband died some time after killing his wife, but his death resulted froma determined effort to kill himself immediately after her death and it is logical to regard this case as a homicide-suicide.

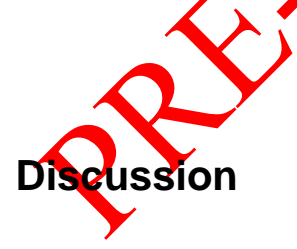

Using the Fol Act was laborious and time consuming. We tried initially to access reports on Authority/ Community Safety Partnership websites, but, even where this was successful, the reports proved difficult to locate and, where age was redacted, we did not know which Reports involved older 
adults. We had planned to consider ethnicity as a factor but ethnicity was usually redacted so this was not feasible. In order to facilitate common learning across DHRs the Home Office (which quality assures all reports) should make Reports readily available for research and practice in one accessible repository. When information about homicides is freely available in the online press, it is not logical to argue that Reports should be kept confidential: sensitive information is redacted. Confidentiality considerations. may be construed to be more in the interests of agencies sensitiye-about aspects of their practice than the interests of public, professionals and potential victims. The main limitations of our study are that we were able to analyse only around $50 \%$ of Reports involving an aderadult and in three cases we used the Executive Summary as we did not have the full Report.

\section{Process and recommendations of DHRs}

The Home Office maintains that where practically possible a DHR should be completed within 6 months of a decision to proceed, but Reports commonly refer to delays in the timescale, and there is a balance between carrying out a detailed and carefyl Review and keeping to a short timescale, especially where essential and speedy changes in systems and practice are required. Ongoing criminal proceedings may affect both access to information during the Review and family involvement. Resources may compromise speedy production of agency management reviews and third sector organisations may need additional support to be involved in the process.

Home Office guidance says: 
"The chair/review panel should make every effort to include the family ...

The involvement of family, friends and others is both necessary and complex as they can have important information about the nature and extent of the abuse which may not have been shared with agencies." (Home Office, 2016a: 17)

Reports demonstrate a range of methods and extents of family involvement. An extended time frame may allow for more sensitivity in involving family and/or friends. Sometimes the circumstances of the homicide make it difficult to involve family. For example:

"The sister of (the perpetrator) has chosento take no part in this review despite attempts to seek herinvolvement. It appears she has indicated her frustration with the care provided for both her brother and mother during the years of his illness." (V22)

"... the homicide had divided the family into two alliances." (V28)

Other issues relevant to the process of Review are: how far back information is soyght and how historical information about previous mental illness is kept andaccessed on the occasion of future illness episodes.

This quotation from one Report sums up the situation with respect to recommendations:

"A cursory analysis of many nationwide mental health homicide inquiries over the last 10 years show the same problems keep 
occurring. Typically these include a failure to communicate effectively between agencies, failure to involve family members, failure to look beyond the symptoms towards the underlying problems to name but a few. The impression we have gained from looking at other reports and from the working experience of panel members is that "learning" not identifying is the main problem." (V16)

We found that DHRs generate numerous similar recommendations, typically including: training of professionals in a wide range of settings; information recording/ record keeping/ information sharing within and between agencies; risk assessment; partnership working; polictes and procedures; and public awareness. The same recommendations are made repeatedly and in different parts of the country suggesting that authorities are not learning from Reviews or are failing to change practice as a result.

A recent Home Office analysis (Home Office, 2016b: 6) of 40 cases (33 involving IRV andsseven AFV) drew recommendations together and stated: the revised statutory guidance on conducting DHRs will invite report authors to record key information of the parties involved, such as age, gender, ethnicity and other characteristics."

This is a useful step forward, as important learning is lost if key information is not accessible for research and practice.

Typology of DA in later life 
Three categories of DA have been postulated in older adults (Cramer and Brady, 2013): DA grown old - DA starts at an early stage in a relationship and persists over time into later life; late onset DA in a new relationship - where the perpetrator is a new spouse or intimate partner; and late onset DA in an established relationship - DA develops anew, eg as a result of relationship stresses later in life or in association with mental illness. In our analysis gnly three Reviews fitted the profile of established DA graduating into later life. In another three homicides there was established DA in other family relationships, which became directed towards the future victipetater in life. Taking a broader family perspective these might also be regarded as constituting DA in later life.

Two homicides involved relationships with hew manipulative criminal partners and would fit into the category or late-dnset DA in a new relationship. The perpetrators with dementia appear to fit into the category of late onset DA in an established relationshipas a result of stresses probably associated with the dementia condition and caring roles.

Gender

Ouranalysis included six homicides where men were the victims. In two homicides a partner or ex-partner (one female, one male) killed the man. One homicide involved a grandfather killed by a grandson with drug/ alcohol misuse problems. Three homicides involved fathers killed by adult sons, two of whom had mental illnesses. 
Globally IPH is dominated by women killed by men. Similarly AFH is gendered with mothers most likely to be killed by their sons (Westmarland, 2015). In a survey of IPV and sexual violence in the United States, lesbian women and gay men reported rates of IPV equal to or higher than those of heterosexual women and men (Walters, Chen and Breiding, 2013). In Australia, Gannoni and Cussen found that same-sex and opposite-sex IPH shared many features, and that men were over-represented as perpetrators in both categories of IPH (Gannoni and Cussen, 2014). Although lesbiaipand gay couples are likely to comprise only a small minority of partnersinvolved in $\mathrm{IPH}$, it is important to consider whether there are additional or different issues that need to be recognised and addressed in thesegroups.

How does age relate to risk of domestic homicide?

A key issue is whether (or how) domestic homicide is different in later life. The four themes identified, namely mental illness of the perpetrator; drug and/ or alcohol abuse; financial issyes; and history of DA in this or other family relationships are also featured in domestic homicides involving younger adults (Home Office, 2016b). In the context of older adults there are likely to be features associated with ageing such as physical ill-health, mental ill-health (incletding dementia), frailty and social concomitants of later life (eg restricted finances, social isolation). However these features may also occur in younger age groups. Our analysis suggests that there is insufficient evidence to conclude that ageing per se is a significant risk factor. The significant factor that emerges from the analysis is the role of assumptions/ prejudices/ 
stereotypes about older age which influence risk assessments and management of potentially abusive situations.

The use of the Domestic Abuse, Stalking and Harassment and Honour Based Violence Risk Identification and Assessment and Management Model (DASH risk assessment) (Richards, 2009) in DA involving older adults may exacerbate the tendency to under-estimate risk. Influential myths here maybe that older people do not engage in aggressive/ violent behaviour and that:

"age is a factor that potentially increases risks to kietims". (P03) Whilst we agree that we need:

"to consider how best to increase awaremess that domestic
violence occurs across the age spectrum through the use of public
education materials" (B11) more research is needed on hor to assess risk in situations of violence involving older people. In particular risk may be underestimated in individuals with physical and or mentay health problems or individuals who are regarded as old and frail. There is also debate about coercive behaviour and whether it is a usefulconcept in relationships involving older people. It is defined as:

Controlling or coercive behaviour does not relate to a single incident, it is a purposeful pattern of behaviour which takes place over time in order for one individual to exert power, control or coercion over another." (Home Office, 2015)

Our clinical experience is that coercion takes place in relationships between older adults and their adult children, but is understood and regarded 
differently. The educational message here is that professionals need to be alerted to, and trained to recognise, such risks in older adults

The role of stereotypes and myths about, dementia

Dementia featured in six of our homicides. In four homicides a person with dementia was the victim and in two the perpetrator. There are myths expressed about dementia in relation to DHRs, in particular an assunption that people with dementia are aggressive and violent towards others and that, as a result, more domestic homicides are likely in future since the population of people with dementia is projected to increase. This is implied in quotations from two cases in our series:

"A joint working group to be developed nvolving all agencies to address the increasing prevalence of dementia to identify the manifestation of harm to themselves or others and management plans to address theseissues". (B06) and "the potential risk of dementia upon levels of domestic abuse" and "the kisk that dementia can pose to the threat of domestic abuse" linking with a recommendation: "Evaluation of CAADA DASH risk assessment checklist to assess if its recognition risk presented by mental health is at the appropriate level in light of the increasing diagnosis of dementia within the U.K. population." (B01)

There is also an opposing myth, that people with dementia are not capable of predetermined acts of violence. 
In our analysis one perpetrator claimed in defence that the victim had dementia:

"During the investigation evidence came to light that (the perpetrator) had been having a relationship with another woman. Police discovered that he had been spreading stories to their friends suggesting that his wife was suffering from some kind of psychological deterioration" (B05)

Another perpetrator claimed to be carer to his victim although there was no evidence that he was undertaking a caring role (V20). Salari) studied intimate partner homicide-suicide and found that $7.5 \%$ of victims had a dementia but that dementia was rare amongst perpetrators (Salari, 2007). Another educational message is for professionals to,recognise (and resist) the influence of contradictory myths (eg older adults do not have the physical capability to commit murder versus all people with dementia are violent and aggressive).

The role of caring

Sharp-effe and Kelly note the importance of caring in both IPV and AFV (Sharp-Jeffs and Kelly, 2016). Failure to involve older parents of psychotic adult children in their care was a feature in our Reports. Are adult children seen as responsible for their own care leading to exclusion of parents? Is this a manifestation of ageism? Is it an example of over-zealous application of confidentiality? 
We suspect that being cared for may be as stressful as doing the caring. In addition a caring situation changes power dynamics between the individuals involved and involves dependency and loss of autonomy. Sometimes the situation is complex as both people involved are caring for one another, or a person might identify as a carer but the person they care for might dispute this. All these factors affect the relationship.

\section{Conclusions}

With respect to our first aim, we have extracted learning relevant to health and social care practitioners working with older adults. The most common action identified in Reports in respect of caring responsiblities is to carry out a carer's assessment, and, whilst this may be helpful and an important message for practitioners, it fails to address the complexity of many caring situations. Training of health and social care professionals needs to address the complexities of caringand the myths and stereotypes that distort risk assessments of older adults: in particular the myths that people with dementia are predisposed to violence, and that frail older adults are not physically capabte of extreme violence.

Could any of these homicides have been prevented? In our view, of 30 homicides, 14 may have been preventable: 11 with changed/ more robust mental health treatment of individuals known to have major mental illness; one with action to relieve aggression from a person with dementia towards their carer; one if the victim had gone into care as she requested and not 
returned home to live with her son; and one if disclosures of abuse had been acted on. This highlights the role of major mental illness and its treatment.

In respect of our second aim, we have investigated the distinctive features of domestic homicides involving older adults and the role of age as a risk factor in domestic homicides. The Home Office analysis (Home Office, 2016b) only included IPH in the main findings since IPH outnumbered AFH in thett sample of DHRs. Although age per se did not emerge as a risk factor in pur analysis, this illustrates the importance of considering age, since AFA featured more prominently in our series of DHRs involving older adults. Collecting and analysing a larger number of reports involving olde addlts would be a first step, and we agree strongly with the recontmendation of another recent review of DHRs (Sharp-Jeffs and Kelly, 2016), which suggested a central repository of DHR reports. The \$harp-Jeffs and Kelly report examined 32 Reports, 24 involved IPH and 8 AFV. Seven of their eight AFV cases involved an adult child killing arant and the eighth a brother killing his brother. The authors list risk factors n family violence cases (p. 70), including: complex intergenerationalyamily context; caring for someone/ being cared for linked with mentalyealth problems; suicidal/ homicidal thoughts; history of previous violence against women/ antisocial behaviour/ previous criminality in the perpetrator; link with "sense of entitlement" including that related to finances; drug/ alcohol abuse; social isolation of victim. These closely link with the themes identified in our analysis and there is a need for more research in this area. To exclude AFV from analysis, when it is linked with age, could be regarded as discriminatory. 
Our analysis finds that age per se is not a significant factor in domestic homicide apart from the way that stereotypes and assumptions about age influence the health and social care assessments made and interventions offered. We need to challenge the stereotypes of domestic abuse, domestic homicide, and ageing in health and social care training and practice. Whilst older adults may be victims of violence, they may also be perpetrators.

Turning to our third aim, we have contributed here to the research literature, and identified a need to standardise terminology in future research relating to abuse and older adults. Currently the terms DA: elder abuse; IPV; AFV/ familial violence; and parental abuse (and.perhaps others) are all used but these categories overlap, complicating resegrch and potentially obscuring important findings (Figure 1 illus(rates the overlaps).

$<$ Figure 1 about here $>$

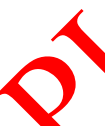

For policy-makers and managers there are some important conclusions. They need to be aware that stereotypes of ageing may affect how domestic homicidès are approached, reviewed and reported, including perhaps influencing whether homicides involving older adults are regarded as domestic homicides and lead to a full DHR. Where a DHR is carried out the review process creates tension between speed and thoroughness. The complexities of domestic homicide argue the need for thoroughness. Where a homicide occurred in a long-standing relationship, setting a short timescale for 
agency chronologies may deprive reviewers of relevant information from the more distant past (eg was there evidence that this man was aggressive earlier in life or has the aggression emerged anew in context in which the homicide took place?) A repository of DHR reports is essential to facilitate annual review and research, and maximise learning. Training about domestic violence and IPV needs to address the particular features relevant to older adults, caring situations, and assessment of risk in respect of older adults.

Finally, we have found that age itself is not a significant factorin domestic homicide, apart from in the way that stereotypes and assumptions about age influence the health and social care assessments made and interventions offered. We need to challenge the stereotype of gomestic abuse ("women caring for young children as victims"), qomestichomicide ("not likely in longlived partner relationships"), and age (ne ("too frail to be violent") in health and social care education, training and pyactice. Older adults may be victims of violence, but they may alsobe perpetrators. Insidious and institutional ageism obscures the impgrant messages for policy-makers, researchers and academics, and pealth and social care practitioners.

\section{Statement of Funding}

This project was unfunded.

\section{Declaration of contribution of authors}

All authors were involved in designing the project and writing the paper. SMB carried out data collection and NVivo analysis. SMB and SB read reports in 
full, reviewed the codings, discussed, modified and developed the thematic analysis. PK reviewed and contributed to discussion of the analysis and conclusions.

\section{Statement of conflict of interest}

Both SMB and PK undertake the roles of DHR Independent Chair/ Author from time to time.

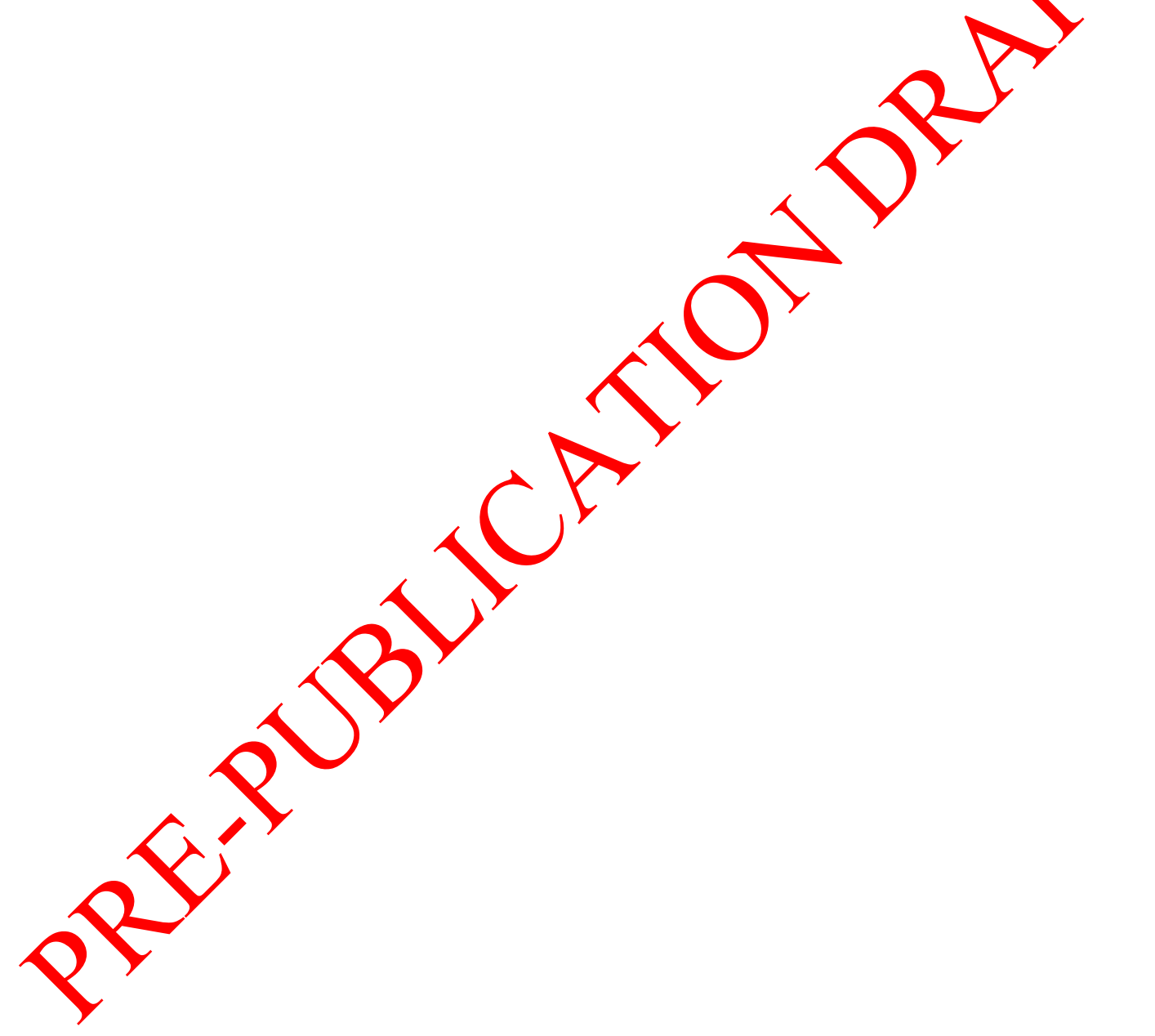




\section{References}

Bazeley, P., and Jackson, K. 2013. Qualitative data analysis with nvivo (2nd ed.).

SAGE Publications Ltd, London.

BMA Board of Science. 2014. Domestic abuse. Retrieved from

https://www.bma.org.uk/collective-voice/policy-and-research/equality/healthcare-forvulnerable-group/domestic-abuse-report

Braun, V., and Clarke, V. (2006) Using thematic analysis in psychology/Qualitative Research in Psychology, 3, 2, 77-101.

Coyne, A. C., Reichman, W. E., and Berbig, L. J. 1993. The relationship between dementia and elder abuse. The American Journal of Psychiatry, 150, 4, 643-646.

Cramer, E. P., and Brady, S. R. 2013. Competing values in serving older and vulnerable adults: Adult protective services, mândated reporting, and domestic violence programs. Journal of Elder Abuse andNeglect, 25, 5, 453-68. doi:10.1080/08946566.2013.78278

Department of Justice Government of Canada. 2015. About family violence. Retrieved from http://wwh ustige.gc.ca/eng/cj-jp/fv-vf/about-apropos.html Eliason, S. 2009. Murder-suicide: A review of the recent literature. Journal of the American Academy of Psychiatry and the Law Online, 37, 3, 371-76.

Gannoni A., and Cussen, T. 2014. Same-sex intimate partner homicide in australia. Trendsand'issues in crime and criminal justice, 469, 1-7.

Home Office. 2015. Controlling or coercive behaviour in an intimate or family relationship statutory guidance framework Retrieved from https://www.gov.uk/government/uploads/system/uploads/attachment data/file/48252 8/Controlling or coercive behaviour - statutory guidance.pdf 
Home Office. 2016a. Multi-agency statutory guidance for the conduct of domestic homicide reviews. Retrieved from

https://www.gov.uk/government/uploads/system/uploads/attachment_data/file/57527 3/DHR-Statutory-Guidance-161206.pdf

Home Office. 2016b. Domestic homicide reviews key findings from analysis of domestic homicide reviews. Retrieved from

http://www.standingtogether.org.uk/sites/default/files/docs/STADV_DHR_Report_Fin al.pdf

Information Commissioner's Office. 2016. The guide to freedom ofinformation. Retrieved from https://ico.org.uk/media/for-organisations/guide/lo-freedom-ofinformation-4-8.pdf

Labrum, T., and Solomon, P. L. 2017. Elder mistreatment perpetrators with substance abuse and/or mental health conditions: results from the National Elder Mistreatment Study. Psychiatric Quarter/Sy Epub ahead of print 23 May 2017. doi:10.1007/s11126-017-9513-z

Liu, P.-J., Conrad, K. J. Beach, S. R., Iris, M., and Schiamberg, L. B. 2017. The importance of investigatind abuser characteristics in elder emotional/psychological abuse: Results from dult protective services data. J Gerontol B Psychol Sci Soc Sci. Epubahead/of print 17 May 2017. doi:https://doi.org/10.1093/geronb/gbx064 Merce C. A., Tanton, C., Prah, P., Erens, B., Sonnenberg, P., Clifton, S., ... Johnson, A. M. 2013. Changes in sexual attitudes and lifestyles in Britain through the life course and over time: findings from the National Surveys of Sexual Attitudes and Lifestyles (natsal). The Lancet, 382, 9907, 1781-1794. 
National Institute for Health and Care Excellence. 2014. Domestic violence and abuse: Multi-agency working. PH50. Retrieved from

https://www.nice.org.uk/guidance/ph50/resources/domestic-violence-and-abusemultiagency-working-1996411687621

Office for National Statistics. 2016a. Intimate personal violence and partner abuse. Retrieved from

https://www.ons.gov.uk/peoplepopulationandcommunity/crimeandjusticefcompendiu m/focusonviolentcrimeandsexualoffences/yearendingmarch2015/chapter4htimatepe rsonalviolenceandpartnerabuse

Office for National Statistics. 2016b. Homicide. Retrieyed from https://www.ons.gov.uk/peoplepopulationandcommunity/crmeandjustice/compendiu m/focusonviolentcrimeandsexualoffences/yearendingmarch2015/chapter2homicide QSR International. 2016. Nvivo 11 pro for windows. Retrieved from http://download.qsrinternational.con/Docd/ment/NVivo11/11.3.0/en-US/NVivo11Getting-Started-Guide-Pro-edition.pdf

Poole, C., and Rietschlin, 2012. Intimate partner victimization among adults aged 60 and older: an analysis of the 1999 and 2004 General Social Survey. Journal of Elder Abuse and Neglect, 24, 2, 120-137. doi:10.1080/08946566.2011.646503 Richards, 2000. Domestic abuse, stalking and harassment and honour based violence (dash, 2009) risk identification and assessment and management model. Retrieved from http://www.dashriskchecklist.co.uk/uploads/pdfs/DASH 2009.pdf Salari, S. 2007. Patterns of intimate partner homicide suicide in later life: Strategies for prevention. Clinical Interventions In Aging, 2, 3, 441-52.

Sharp-Jeffs, N., and Kelly, L. 2016. Domestic homicide review (dhr) case analysis. Retrieved from 
http://www.standingtogether.org.uk/sites/default/files/docs/STADV_DHR_Report_Fin al.pdf

Stöckl, H., Devries, K., Rotstein, A., Abrahams, N., Campbell, J., Watts, C., and Moreno, C. G. 2013. The global prevalence of intimate partner homicide: A systematic review. The Lancet, 382, 9895, 859-865.

The Care Act. 2014. Care Act. Retrieved from http://www.legislation.gov.uk/ukpga/2014/23/pdfs/ukpga_20140023_enpdf Tobiasz-Adamczyk, B., Brzyski, P., and Brzyska, M. 2014. Health-related quality of life in older age and a risk of being a victim of domestic violence.Archives of Gerontology and Geriatrics, 58, 388-398.

Walters, M. L., Chen, J. and Breiding, M. J. 2013. Thenational intimate partner and sexual violence survey 2010 findings on victinfizationby sexual orientation. Retrieved from https://www.cdc.gov/violenceprevention/nisvs/specialreports.html Westmarland, N. 2015. Violence against hoothers and grandmothers Violence against women criminologicakperspectives on men's violences. Routledge, Abingdon, Oxon, 51-60

Wilke, D. J., and Vinton. L. 2005. The nature and impact of domestic violence across age cohorts. Affilia, 20, 316-328.

World Health Organisation. 2012. Intimate partner violence. Retrieved from http://apps.who.int/iris/bitstream/10665/77432/1/WHO_RHR_12.36_eng.pdf World Health Organisation. 2014. Global status report on violence prevention 2014. Retrieved from http://www.undp.org/content/dam/undp/library/corporate/Reports/UNDP-GVAviolence-2014.pdf 
World Health Organisation. 2016a. Violence against women intimate partner and sexual violence against women Retrieved from http://www.who.int/mediacentre/factsheets/fs239/en/ World Health Organisation. 2016b. Elder abuse. Factsheet. Retrieved from http://www.who.int/mediacentre/factsheets/fs357/en/ Yan, E., and Chan, K. L. 2012. Prevalence and correlates of intimate partner violence among older Chinese couples in Hong Kong. International Psychogexjatrics, 24, 9, 1437-1446. doi:10.1300/J084v19n01_02 Yon, Y., Wister, A. V., Mitchell, B., and Gutman, G. 2014. A nationalcomparison of spousal abuse in mid- and old age. Journal of Elder Abyse \& Neglect, 26, 1, 80-105. doi:10.1080/08946566.2013.784085 Yon, Y., Mikton, C., Gassoumis, Z. D., and Wither,K.H. 2017. The prevalence of self-reported elder abuse among older womenin community settings: a systematic review and meta-analysis. Trauma, Violehce, and Abuse, 1-15. Epub ahead of print 10 April 2017. doi:https://doi.org/10.1177/1524838017697308

Correspondense address for corresponding author: Dr Susan M Benbow, Visiting Professor Mental Health and Ageing, Centre for Ageing Studies, University of Chester, Riverside Campus, Chester, CH1, 1SL, UK. 
Table 1: Basic details of the homicides

\begin{tabular}{|c|c|c|c|c|}
\hline Characteristic & $\begin{array}{l}\text { Victim and } \\
\text { perpetrator both } \\
\text { aged } 60 \text { plus }(n=7)\end{array}$ & $\begin{array}{l}\text { Perpetrator only } \\
\text { aged } 60 \text { plus }(n=6)\end{array}$ & $\begin{array}{l}\text { Victim only aged } 60 \text { plus } \\
(n=17)\end{array}$ & $\begin{array}{l}\text { Homicide- suicides } \\
(n=5)\end{array}$ \\
\hline $\begin{array}{l}\text { Gender of } \\
\text { victim }\end{array}$ & All women & All women & $\begin{array}{l}\text { Women } 11 \\
\text { Men } 6\end{array}$ & All women \\
\hline $\begin{array}{l}\text { Gender of } \\
\text { perpetrator }\end{array}$ & All men & All men & $\begin{array}{l}\text { Men } 16 \\
\text { Women } 1 \text { (assisted by a man) }\end{array}$ & $\begin{array}{l}\text { All men who then } \\
\text { killed themselves }\end{array}$ \\
\hline $\begin{array}{l}\text { Relationship (to } \\
\text { victim) }\end{array}$ & All spouse/ partners & $\begin{array}{l}\text { All spouses/ partners } \\
\text { or ex spouse/ partners }\end{array}$ & $\begin{array}{l}\text { Adult child } 12 \\
\text { Adult grandachild } 2 \\
\text { Spouse/ partner } 2 \\
\text { Ex spouse/partner } 1\end{array}$ & $\begin{array}{l}\text { All spouses/ partners } \\
\text { or ex spouse/ } \\
\text { partners }\end{array}$ \\
\hline Age of victim & $62-82$ mean 72 & 46-58 mean 53 & $60-91$ mean 72 & $56-80$ \\
\hline $\begin{array}{l}\text { Age of } \\
\text { perpetrator }\end{array}$ & $61-79$ mean 70 & $60-72$ mean 64 & & $60-79$ \\
\hline Dementia? & $\begin{array}{l}1 \text { victim } \\
2 \text { perpetrators }\end{array}$ & 0 & Dementia/ ?dementia 3 & 1 victim \\
\hline $\begin{array}{l}\text { Other mental } \\
\text { illness }\end{array}$ & $\begin{array}{l}3 \text { depression } \\
1 \text { probable } \\
\text { psychosis }\end{array}$ & $\begin{array}{l}\text { Victims: dep } \\
\text { anxiety } 4 / 6\end{array}$ & $\begin{array}{l}\text { Victims: depression/ anxiety 2; } \\
\text { Perpetrators: psychosis/ schizophrenia } \\
\text { 6; } \\
\text { Personality disorder 3; } \\
\text { Depression/anxiety 1; } \\
\text { Mental Health disorder } 2\end{array}$ & $\begin{array}{l}\text { Victims: depression/ } \\
\text { anxiety } 1 \\
\text { Perpetrators: } \\
\text { Depression } 4 \\
\text { Psychosis } 1\end{array}$ \\
\hline $\begin{array}{l}\text { Alcohol/ drug } \\
\text { abuse? }\end{array}$ & Not a feature & & $\begin{array}{l}\text { Victims } 4 \text { alcohol } \\
\text { Perpetrators } 9 \text { drug/ alcohol use } \\
\text { Neither } 5\end{array}$ & $\begin{array}{l}\text { Perpetrator } 1 \text { alcohol } \\
\text { Neither } 4\end{array}$ \\
\hline $\begin{array}{l}\text { Length of } \\
\text { relationship }\end{array}$ & $\begin{array}{l}5 / 7 \text { relationship } \\
\text { years duration } \\
\text { (others } 24 \text { ands } \\
\text { yrs) }\end{array}$ & $\begin{array}{l}3 / 6 \text { relationship }>30 y r s \\
\text { duration } \\
\text { (others } 6,14 \text { and } n / k \\
\text { yrs) }\end{array}$ & & $\begin{array}{l}4 / 5 \text { relationship } \\
>35 y \text { rs } \\
1 / 5 \text { not known }\end{array}$ \\
\hline Homicide- & $3 / 7$ & $2 / 6$ & $0 / 17$ & $5 / 5$ \\
\hline
\end{tabular}




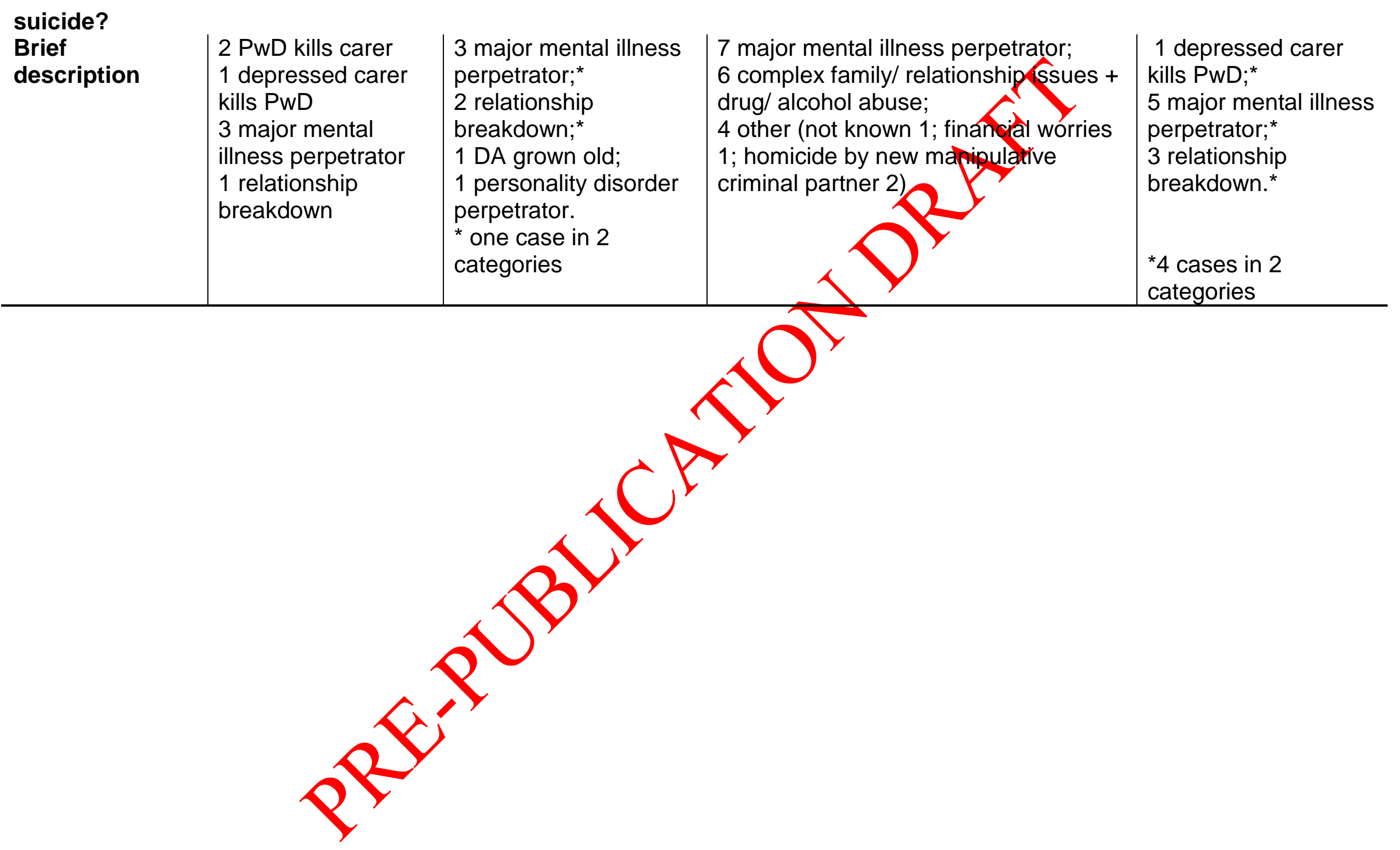




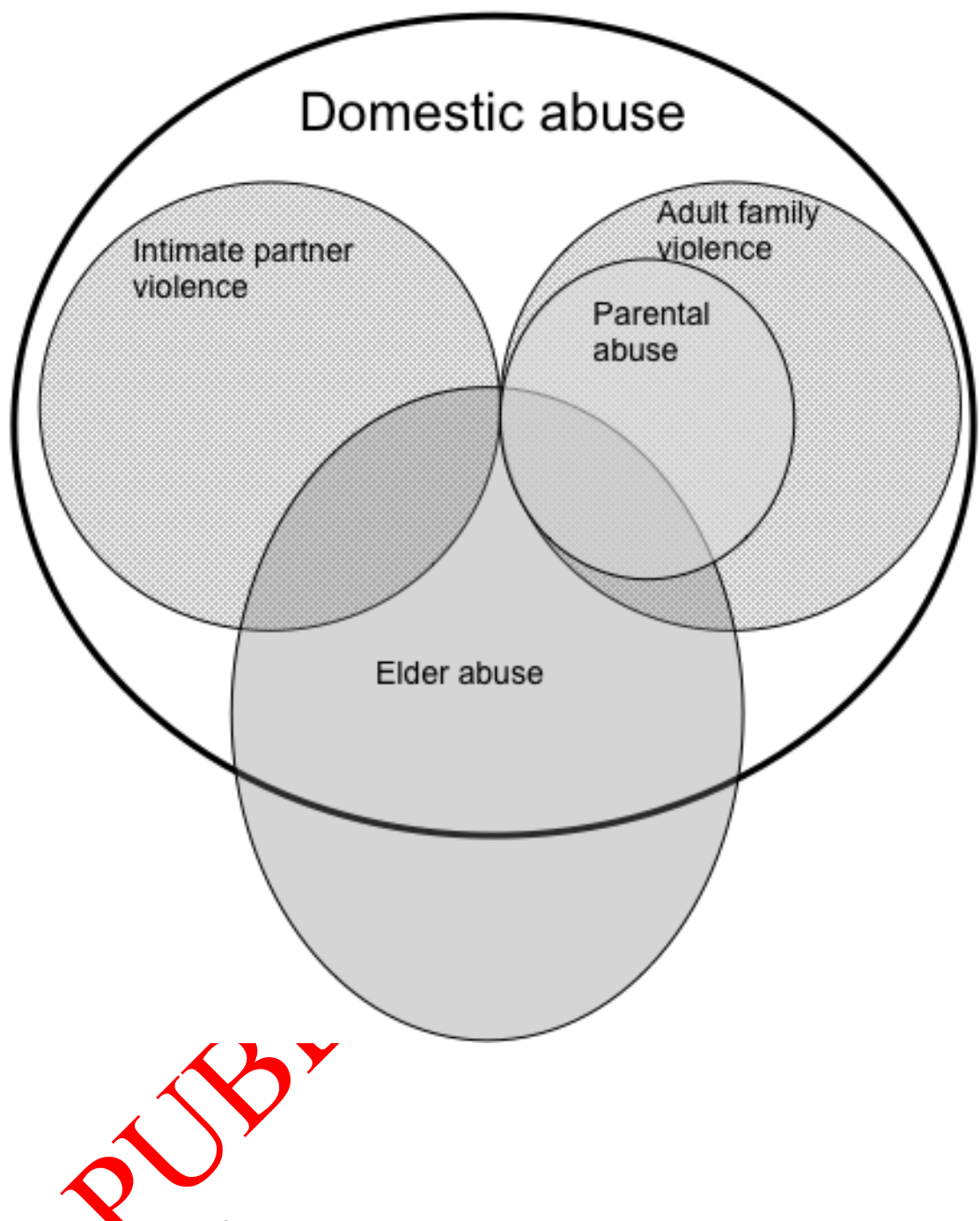

Figure 1: Representation of the overlapping terminology in relation to older adults and abuse/ violence

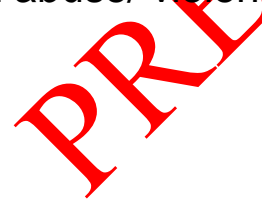

